\title{
Potential of the cryoplane technology to reduce aircraft climate impact: A state-of-the-art assessment
}

\author{
Michael Ponater ${ }^{\mathrm{a}, *}$, Susanne Pechtl ${ }^{\mathrm{b}}$, Robert Sausen ${ }^{\mathrm{a}}$, \\ Ulrich Schumann ${ }^{\mathrm{a}}$, Gerhard Hüttig ${ }^{\mathrm{c}}$ \\ anstitut für Physik der Atmosphäre, DLR Oberpfaffenhofen, D-82230 Wessling, Germany \\ ${ }^{\mathrm{b}}$ Institut für Unweltphysik, Universität Heidelberg, D-69120 Heidelberg, Germany \\ ${ }^{\mathrm{c}}$ Institut für Luft-und Raumfahrt, TU Berlin, D-10587 Berlin, Germany
}

Received 22 February 2006; received in revised form 13 June 2006; accepted 14 June 2006

\begin{abstract}
The potential reduction in climate impact due to a switch from kerosene supported aviation to liquid hydrogen $\left(\mathrm{LH}_{2}\right)$ supported aviation (cryoplanes) is assessed. Different scenarios for a respective gradual technology transition between 2015 and 2050 are provided. State-of-the-art simulations of three-dimensional (3D) radiative forcing (RF) distributions are compiled and complemented for the various agents determining aviation climate impact. They are utilized to quantify the globally averaged transient climate response and respective differences between the transition scenarios. A climate impact reduction of between $15 \%$ and $50 \%$ in terms of RF is indicated for the cryoplane scenarios at the 2050 time slice, with a best estimate near $30 \%$ in case of a swift transition. The respective reduction range is between $5 \%$ and $15 \%$ in terms of surface temperature change, with a best estimate of about $10 \%$. The environmental benefit of a cryoplane transition further increases if time horizons beyond 2050 are considered. Besides known uncertainties in quantifying aviation climate impacts, crucial limitations of our assessment are insufficient knowledge on contrail cirrus induced by cryoplanes and on the feasibility to produce large amounts of $\mathrm{LH}_{2}$ from renewable energy sources.
\end{abstract}

(C) 2006 Elsevier Ltd. All rights reserved.

Keywords: Aircraft climate impact; Alternative fuels; Technology transition

\section{Introduction}

Current civil aviation is responsible for just $2 \%$ of total anthropogenic $\mathrm{CO}_{2}$ emissions. However, as aviation is among the fastest growing economic sectors, its impact on environment and climate has been a matter of special concern in the context of anthropogenic global warming. It has been stated in

\footnotetext{
*Corresponding author. Tel.: + 498153282539 ; fax: +4981531841 .

E-mail address: michael.ponater@dlr.de (M. Ponater).
}

a number of assessments (e.g., Brasseur et al., 1998; Penner et al., 1999; Schumann et al., 2001; Sausen et al., 2005) that the total climate impact of current aviation is, in terms of radiative forcing (Shine et al., 1990; Ramaswamy et al., 2001), at least twice as large as the contribution from aircraft $\mathrm{CO}_{2}$ emissions alone. The excess is caused by the forcing components contributed by persistent contrails and by aircraft $\mathrm{NO}_{x}$, water vapour, and particle emissions. Technological and operational mitigation options to reduce aircraft climate impact have thus been discussed: For example, optimization of flight 
altitude, or flight routing in general, may lead to an environmental gain with respect to ozone forcing (e.g., Grewe et al., 2002b; Gauss et al., 2006) as well as contrail forcing (e.g., Williams et al., 2003; Fichter et al., 2005; Mannstein et al., 2005).

One technological option to reduce the aviation impact on climate is a switch to alternative fuels such as liquid hydrogen $\left(\mathrm{LH}_{2}\right)$. This so-called cryoplane technology would eliminate particle and $\mathrm{CO}_{2}$ emissions, at least if $\mathrm{LH}_{2}$ can be produced without using fossil energy sources. $\mathrm{A} \mathrm{NO}_{x}$ emission index (EI) lower than for conventional kerosene engines may also be expected due to the extended possibility to employ lean fuel burning (e.g., the "micromix combustion technology" described by Dahl and Suttrop, 1998). However, $\mathrm{LH}_{2}$ engines would emit more water vapour, and so also facilitate thermodynamic contrail formation (Schumann, 1996). Hence, a quantitative comparison of the climate impacts from either kerosene or $\mathrm{LH}_{2}$ technology must cover all components of the aircraft impact. Marquart et al. (2001) gave a first estimate, which identified contrails as the one aviation impact that may thwart an environmental gain from cryoplane operation. However, they had to avoid definite conclusions, as only differences in contrail coverage but not in microphysical properties were considered. In recent years the state of knowledge has improved due to international research projects like the EU-projects "TRADEOFF" and "CRYOPLANE". The present assessment improves over previous work in several ways: first, sensible technology transition scenarios have been developed to replace the more idealized assumptions of Marquart et al. (2001). Second, the contrail impact is treated more comprehensively by including model results that indicate different contrail microphysical properties for cryoplanes and conventional aircraft (Ström and Gierens, 2002; Marquart et al., 2005). Third, our study will extend to global surface temperature changes (beyond radiative forcing (RF)), which is a more straightforward parameter to represent climate change. Moreover, the consequences of differences in forcing "efficacy" (Hansen et al., 2005), i.e., the specific sensitivity of the global climate system to individual aircraft impact components can be included. We emphasize the global perspective of our assessment: regional specifics of aircraft climate impact will not be addressed.

Section 2 will describe the data, tools, and methods which have been applied. Section 3 will provide an overview of the key parameters that have been used to quantify the various aspects of aircraft climate impact, giving either suitable reference to previous publications or describing new scientific results yielded within the scope of this study. In Section 4 the individual key parameters will be used as input to a $1 \mathrm{D}$ (global) climate response model to achieve an overall global assessment of the potential consequences of the technology switch during and at the end of the transition period. The paper concludes with a discussion emphasizing the merits and limitations of this assessment.

\section{Method and tools}

We use a combination of model tools in order to convert information about the future development of aircraft emissions into information on a potential climate response, roughly following the way of proceeding introduced in the IPCC special report "Aviation and the global atmosphere" (Penner et al., 1999). Approved aircraft inventories and scenarios are applied (DLR-1992, DLR-2015, FESG/Fa1-2050, see Penner et al., 1999, and references therein) that include both civil and military aviation. To quantify atmospheric impacts our assessment relies on state-of-the-art model configurations which will be described in the following subsections. As future projections of emissions and climate parameter changes must necessarily be based on model results, we emphasize that results simulated with the respective tools under present day conditions have been evaluated by in situ and satellite measurements wherever possible (e.g., Grewe et al., 2001; Schumann et al., 2001; Meyer et al., 2006).

\subsection{General circulation and climate model}

In order to provide a transient projection of aviation related climate change, we first need scenarios for the various emissions. Second, estimates of the global mean RF for all contributing agents must be known for some key years within the period to be projected. This study mainly relies on RF results that have been obtained from several simulations with the three-dimensional (3D) global climate model ECHAM4. A nearly complete set of aviation related RF calculations for the years 1992, 2015, and 2050 is available from this model, always employing the approved 3D aircraft emission inventories that were also used for the IPCC report 
(Penner et al., 1999). An overview on the simulation results will be given in Section 3. The ECHAM4 general circulation model (Roeckner et al., 1996) and its extensions to simulate specific responses to aircraft emissions have been described in detail elsewhere (see also Section 3). ECHAM4 includes state-of-the-art atmospheric physics and is available in a version coupled to a model of stratospheric and tropospheric chemistry (Hein et al., 2001; Grewe et al., 2001). The 3D aviation impact studies described below have been simulated with moderate horizontal resolution (spectral T30) but with enhanced vertical resolution (Land et al., 1999) to capture strong gradients in the upper troposphere/ lower stratosphere (UTLS) region where aviation emissions are mainly released. Results from the ECHAM4 model have contributed substantially to the environmental impact assessments for conventional, kerosene supported, aviation (as cited in the introduction). However, due to apparent model dependencies of the impact of many aircraft perturbations, results from other model studies will also be considered to account for the RF uncertainty range.

The RF values given in this paper follow the usual definition of the "stratosphere adjusted RF at the tropopause", which is regarded to be the most appropriate way for inter-comparing the impact of individual climate perturbations (Shine et al., 1990; Penner et al., 1999). These values can be calculated consistently in ECHAM4 applying the technique described by Stuber et al. (2001). 3D distributions of RF have generally been determined from simulations extending over a few years. They lead to statistically robust global mean forcing values. However, in order to determine with sufficient statistical accuracy a climate sensitivity parameter $\lambda$ via

$\Delta T_{\mathrm{sfc}}^{(\mathrm{eq})}=\lambda \cdot \mathrm{RF}$

we had to perform simulations (at least one for each contributing agent) long enough to obtain a robust global mean surface temperature response $\Delta T_{\mathrm{sfc}}^{(\mathrm{eq})}$ from the background climate variability. The values of $\lambda$ for the various aviation related agents are summarized in Table 1 . They represent equilibrium climate sensitivity parameters (e.g., Ramaswamy et al., 2001) that were derived from 30-year simulations with the ECHAM4 version of Land et al. (1999), coupled to a mixed layer ocean model. Values of the climate sensitivity parameter for $\mathrm{CO}_{2}$
Table 1

Climate sensitivity parameters $\left(\lambda\right.$, in $\left.\mathrm{K} /\left(\mathrm{W} \mathrm{m}^{-2}\right)\right)$ and efficacy values $(r)$ as determined from ECHAM4 equilibrium climate change simulations for different aviation impact components (see text)

\begin{tabular}{llllll}
\hline & $\mathrm{CO}_{2}$ & $\mathrm{O}_{3}$ & $\mathrm{CH}_{4}$ & $\mathrm{H}_{2} \mathrm{O}$ & Contrails \\
\hline$\lambda$ & 0.73 & 1.00 & 0.86 & 0.83 & 0.43 \\
$r$ & 1.00 & 1.37 & 1.18 & 1.14 & 0.59 \\
\hline
\end{tabular}

and for contrails have been discussed in Ponater et al. (2005), and those for $\mathrm{CH}_{4}$, aircraft $\mathrm{H}_{2} \mathrm{O}$, and aircraft ozone have been determined by dedicated simulations for this study. As evident from Table 1 the largest deviation from the $\mathrm{CO}_{2}$ climate sensitivity occurs for contrails (lower) and aviation induced ozone change (higher). The maximum deviations are of the order of $40 \%$, consistent with the $\lambda$ range found by Hansen et al. (2005) from a multitude of simulations for mainly non-aviation related forcings.

\subsection{Global linear response model}

In cases where the reaction of the climate system shows a substantial delay relative to the time development of the forcing, the linear response model of Sausen and Schumann (2000) has been applied to calculate a realistic global mean response for a given time horizon. This is important, e.g., in order to determine the $\mathrm{CO}_{2}$ concentration change from aircraft $\mathrm{CO}_{2}$ emissions (because of the long atmospheric lifetime) or to calculate the surface temperature response to some RF (because of the thermal inertia of the oceans in the climate system). The model has been appropriately tuned to reproduce the relaxation times found in comprehensive transport and climate models. We are aware that these relaxation times are itself uncertain to some extent. However, our main interest here is in the relative difference of various transient scenarios rather than in an optimal capture of the actual future evolution. The $\mathrm{CO}_{2}$ and ozone forcings are treated as explained by Sausen and Schumann (2000). Like for $\mathrm{NO}_{x}$ emissions and ozone forcing, we assume a synchronous temporal evolution of emissions and climate forcing also for aircraft water vapour: aircraft at conventional flight altitudes mainly change water vapour in the lowermost stratosphere where accumulation times are still small. Assumption of a quasi-instantaneous forcing is straightforward for contrails. The linear response 
model also includes expected future changes of the EI for $\mathrm{NO}_{x}$ and changes of the overall propulsion efficiency for contrails (Schumann, 2000, 2001). The assumed values are summarized in Table 2, further details will be described in Section 3. In order to account for the evidence of a distinctive climate sensitivity parameter for the various perturbations, Eq. (8) of Sausen and Schumann (2000) for the transient global temperature response (calculated through the convolution integral of a normalized $\mathrm{RF}^{*}$ and the system's Green's function $G$ ) has been modified to

$\Delta T_{\mathrm{sfc}}(t)=r \int_{0}^{t} G\left(t-t^{\prime}\right) \cdot \mathrm{RF}^{*}\left(t^{\prime}\right) \mathrm{d} t^{\prime}$

now including specific efficacy factors $r_{i}=\left(\lambda_{i} / \lambda_{\mathrm{CO}_{2}}\right) . \lambda_{i}$ indicates the climate sensitivity parameter for some non- $\mathrm{CO}_{2}$ aircraft forcing $i$ (Table 1).

By employing the linear response model to calculate the differences between the global mean time-dependent responses for the different transition scenarios we avoid using the global warming potential (Shine et al., 1990). This metric to compare individual contributors to a net climate impact has also been adopted to assess aviation effects (e.g., Svensson et al., 2004), but has been questioned for the reason of its ambiguities if forcings with distinct spatial and temporal structure are to be quantified (e.g., Penner et al., 1999; Fuglestvedt et al., 2003; Shine et al., 2005a). A simple but still fully appropriate metric for comparing the climate impact of long-lived and short-lived agents has yet to be developed (e.g., Berntsen et al., 2005; Shine et al., 2005b; Forster et al., 2006).

\subsection{Transition scenarios}

An instantaneous technology switch at some arbitrary year was assumed in the pilot study of Marquart et al. (2001) for a first estimate of potential impact changes. In the present study we use more elaborated scenarios of a gradual technology transition from the CRYOPLANE project (Hüttig et al., 2001). Four transition scenarios (Ker, Cryo1, Cryo2, and Cryo3) are evaluated, where Ker indicates the standard, purely kerosene supported, future projection of aircraft emissions (see above). We calculate the climate impact and response for the period from 1940 to 2050, which is covered by the aviation inventories and projections used in the IPCC report (Penner et al., 1999). The technology transition in two cryoplane scenarios is assumed to begin in 2015: Cryol represents a smooth stepwise transition approach with the EU taking the lead, followed 5 years later by a transition start in North America, and another five years later in South America, Asia and the Middle East. Introduction of cryoplanes in all regions starts with the smallest aircraft, while long-range aircraft follow about 10 years later. Cryo2 assumes a fast transition, starting with a gradual world-wide transition of small and medium-sized aircraft in 2015 and of large aircraft in 2025. This scenario implies a complete switch to hydrogen fuel in 2050 . Cryo3 starts a world-wide transition later 2020 but proceeds as fast as Cryo 2 towards the end of the period. Even though these transition scenarios are unlikely to be actually realized within the time frame described above, they account for the transient character of a possible technology switch and allow to develop an impression how much the environmental gain will depend on the speed of the transition.

In all cases the absolute fuel consumption, in terms of mass units of kerosene equivalents (ke), is assumed to develop according to the kerosene reference scenario (Ker), while the transition scenarios (every fifth year) provide information on the relative $\mathrm{LH}_{2}$ fuel consumption $k$ and kerosene fuel consumption $(1-k)$. Annual values are yielded through linear interpolation. Fig. 1 displays

Table 2

Input parameters for the linear response model: $\mathrm{NO}_{x}$ emission index (in $\mathrm{g}\left(\mathrm{NO}_{2}\right)$ per $\mathrm{kg}$ kerosene equivalent) and overall propulsion efficiency $\eta$ for pure conventional aviation and pure cryoplane aviation

\begin{tabular}{|c|c|c|c|c|c|c|c|}
\hline & \multicolumn{2}{|l|}{1992} & \multicolumn{2}{|l|}{2015} & \multicolumn{2}{|l|}{2050} & \multirow[t]{2}{*}{ Reference } \\
\hline & Conv. & Cryopl. & Conv. & Cryopl. & Conv. & Cryopl. & \\
\hline $\mathrm{EI}\left(\mathrm{NO}_{x}\right)$ & 12.0 & - & 15.0 & 4.5 & 6.0 & 1.5 & $\begin{array}{l}\text { Penner et al. (1999), } \\
\text { Klug (2001) }\end{array}$ \\
\hline$\eta$ & 0.3 & 0.3 & 0.4 & 0.4 & 0.5 & 0.5 & Schumann (2000) \\
\hline
\end{tabular}


the temporal development of global kerosene consumption, the difference between the transition scenarios and Ker indicate the increasing $\mathrm{LH}_{2}$ consumption in ke. The corresponding $\mathrm{CO}_{2}, \mathrm{H}_{2} \mathrm{O}$, and $\mathrm{NO}_{x}$ emissions can be calculated assuming the appropriate emission indices for either fuel component (see Section 3). As an example, global $\mathrm{CO}_{2}$ emissions in units of $\operatorname{Tg}(\mathrm{C}) \mathrm{a}^{-1}$ are yielded by multiplying the values of Fig. 1 by 0.86 , using an $\mathrm{CO}_{2}$ emission index of $3.15 \mathrm{~kg} \mathrm{~kg}^{-1}$ (ke) for kerosene. We note that equivalent fuel consumption (in ke) may be an assumption slightly in favour of the cryoplane technology, as indications of a sizedependent fuel use excess of around $10 \%$ have been derived from possible differences in aerodynamics and flight weight (Slingerland, 2005).

\section{Climate impact of individual aviation emissions}

This section describes our quantitative treatment of individual aviation effects, reconciling results

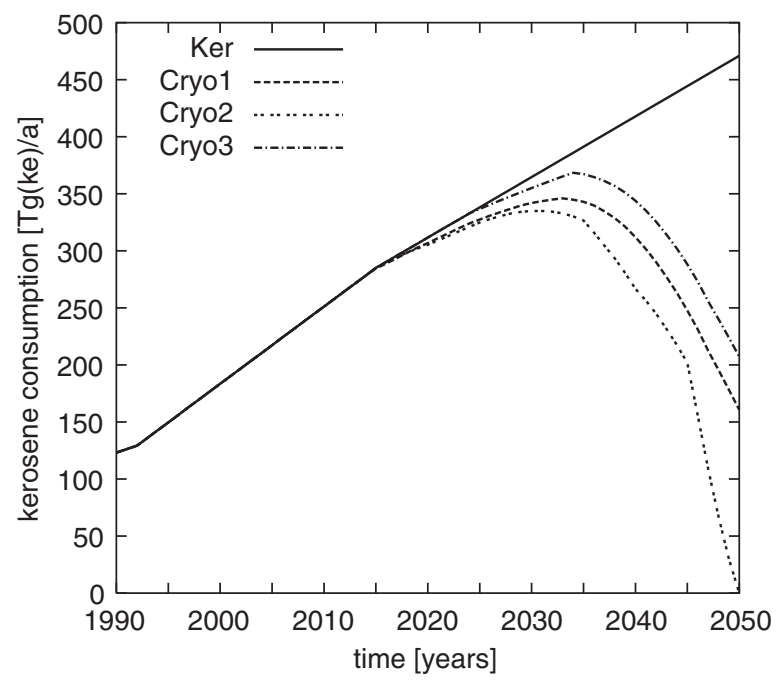

Fig. 1. Time development of kerosene fuel consumption between 1990 and 2050 for a scenario purely based on conventional aircraft technology (Ker) and three scenarios of transition to the cryoplane technology (Cryol/2/3, see text). from previous and new 3D simulations, and describing in detail the way these results are utilized in the linear response model. The possible feedback of a background climate change on, e.g., ozone production rates (Grewe et al., 1999; Stevenson et al., 2000) or contrail formation (Marquart et al., 2003) will not be accounted for, because respective results are not available in all cases. For all aircraft impact components, the global mean RF in a transition scenario linearly combines the RF contributed from the conventional and from the cryoplane part of fleet:

$\mathrm{RF}(t)=(1-k) \cdot \mathrm{RF}_{\text {conv }}(t)+k \cdot \mathrm{RF}_{\text {cryo }}(t)$.

We further note that, to avoid the use of very small numbers in the text, we will usually give the aircraft climate impact in $\mathrm{mW} \mathrm{m}^{-2}\left(10^{-3} \mathrm{~W} \mathrm{~m}^{-2}\right)$ for $\mathrm{RF}$, and in $\mathrm{mK}\left(10^{-3} \mathrm{~K}\right)$ for surface temperature change.

\subsection{Greenhouse gases: $\mathrm{CO}_{2}$ and $\mathrm{H}_{2} \mathrm{O}$}

The primary environmental gain of the cryoplane technology is caused by the complete avoidance of $\mathrm{CO}_{2}$ emissions. Table 3 summarizes the key input values of fuel consumption and $\mathrm{CO}_{2}$ emissions given to the linear response model in order to calculate aviation related $\mathrm{CO}_{2}$ concentration change, $\mathrm{RF}$, and surface temperature change. As soon as the transition from kerosene to $\mathrm{LH}_{2}$ begins, $\mathrm{CO}_{2}$ emissions will be reduced. Due to the long atmospheric lifetime of $\mathrm{CO}_{2}$, its atmospheric concentration (as well as its RF) changes more slowly, which is reflected in the results of the response model as discussed in Sausen and Schumann (2000). Fig. 2 shows how all cryoplane transition scenarios inhibit smaller $\mathrm{CO}_{2}$ concentration increases than found in Ker. However, only in Cryo 2 an actual concentration decrease occurs some years before 2050, indicating that the global $\mathrm{CO}_{2}$ sink begins to dominate over the remaining aviation $\mathrm{CO}_{2}$ source. The time development of $\mathrm{CO}_{2}$ related RF (see Section 4) closely follows that of the $\mathrm{CO}_{2}$ concentration. As in Sausen

Table 3

Input parameters for the linear response model: fuel consumption (in $\mathrm{Tg}$ kerosene equivalent (ke) per year) and $\mathrm{CO}_{2}$ emissions (in $\mathrm{Tg}$ carbon per year) of either pure conventional aviation or pure cryoplane air traffic

\begin{tabular}{|c|c|c|c|c|c|c|c|}
\hline & \multicolumn{2}{|l|}{1992} & \multicolumn{2}{|l|}{2015} & \multicolumn{2}{|l|}{2050} & \multirow[t]{2}{*}{ Reference } \\
\hline & Conv. & Cryopl. & Conv. & Cryopl. & Conv. & Cryopl. & \\
\hline Fuel $\left(\operatorname{Tg}(\mathrm{ke}) \mathrm{a}^{-1}\right)$ & 129.3 & 129.3 & 285.0 & 285.0 & 471.0 & 471.0 & Penner et al. (1999) \\
\hline $\mathrm{CO}_{2}\left(\operatorname{Tg}(\mathrm{C}) \mathrm{a}^{-1}\right)$ & 111.2 & 0 & 245.1 & 0 & 405.1 & 0 & Penner et al. (1999) \\
\hline
\end{tabular}




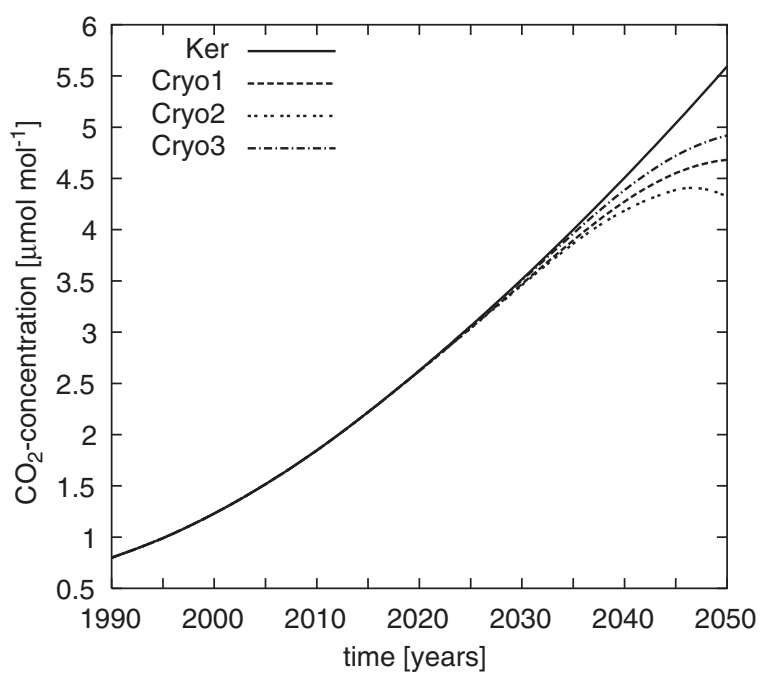

Fig. 2. As Fig. 1 but for aircraft induced $\mathrm{CO}_{2}$ concentration changes.

and Schumann (2000) consistent background $\mathrm{CO}_{2}$ change are taken into account to yield a most reliable estimate for the RF of aviation $\mathrm{CO}_{2}$. For aviation $\mathrm{CO}_{2}$ the state of knowledge to quantify the climate impact can be regarded as good (Penner et al., 1999; Sausen et al., 2005). Thus, there is no need to accompany our respective (best) estimate by maximum and minimum options.

The other greenhouse gas change directly caused by aircraft emissions is water vapour accumulation in the UTLS region. The EI of $\mathrm{H}_{2} \mathrm{O}$ is higher for $\mathrm{LH}_{2}$ engines than for kerosene engines (3.21 $\mathrm{kg}\left(\mathrm{H}_{2} \mathrm{O}\right) / \mathrm{kg}(\mathrm{ke})$ and $1.26 \mathrm{~kg}\left(\mathrm{H}_{2} \mathrm{O}\right) / \mathrm{kg}(\mathrm{ke})$, respectively). As long as aircraft cruising is restricted to flight levels in and below the UTLS (and not shifted to altitudes around $20 \mathrm{~km}$ as discussed by, e.g., Kinnison et al., 2001), accumulation of emitted water vapour has been assessed as a contribution of minor importance in the IPCC report (Penner et al., 1999). The cryoplane impact first estimate of Marquart et al. (2001) also concluded that the water vapour component to total RF is negligible, but more recent studies (Gauss et al., 2003; Morris et al., 2003) have indicated a more substantial aviation induced $\mathrm{H}_{2} \mathrm{O}$ concentration increase. It is conceivable that in the ECHAM4 simulations of Marquart et al. (2001) the parameterized water vapour sink (through condensation and subsequent sedimentation) in the UTLS was too strong due to an overestimated background water vapour around the tropopause. On the other hand, Gauss et al. (2003) and Morris et al. (2003) did not assume any stratospheric sink at all, which might have lead to overestimated water vapour accumulation despite of their models employing superior advection schemes. For the present study we repeated some of the simulations of Marquart et al. (2001) with a modified ECHAM4 version (see Ponater et al., 2006, for details) which is much less affected by the background water vapour excess than the standard ECHAM4. As an example, Fig. 3 shows the resulting aviation related $\mathrm{H}_{2} \mathrm{O}$ increase arising from a hypothetical air-fleet, using 2015 emission data and assuming pure cryoplane operation. This figure forms a direct counterpart to Fig. 5 of Gauss et al. (2003). Our new RF estimate is significantly larger than that derived by Marquart et al. (2001) but still hardly half as large as derived by Gauss et al. (2003). We select this triplet of values (Table 4) as the key input (best, minimum, maximum estimate, respectively) for calculating the development of the RF contribution caused by aviation related $\mathrm{H}_{2} \mathrm{O}$ increase. The actual equation reads, in analogy to Sausen and Schumann's (2000) Eq. (12) for the ozone RF

$$
\begin{aligned}
\mathrm{RF}_{\mathrm{H}_{2} \mathrm{O}}(t)= & S_{\mathrm{H}_{2} \mathrm{O}} \cdot\left[(1-k) \cdot \frac{\mathrm{EI}\left(\mathrm{H}_{2} \mathrm{O}\right)_{\text {conv }}}{\mathrm{EI}\left(\mathrm{H}_{2} \mathrm{O}\right)_{\text {cryo }}}+k\right] \\
& \cdot \frac{E_{a}(t)}{E_{a}(2015)},
\end{aligned}
$$

where $S_{\mathrm{H}_{2} \mathrm{O}}$ indicates the RF values from Table 4 , the $\mathrm{EI}\left(\mathrm{H}_{2} \mathrm{O}\right)$ values are the water vapour emission indices for kerosene and hydrogen fuel, respectively, and $E_{a}(t)$ indicates the aircraft fuel consumption.

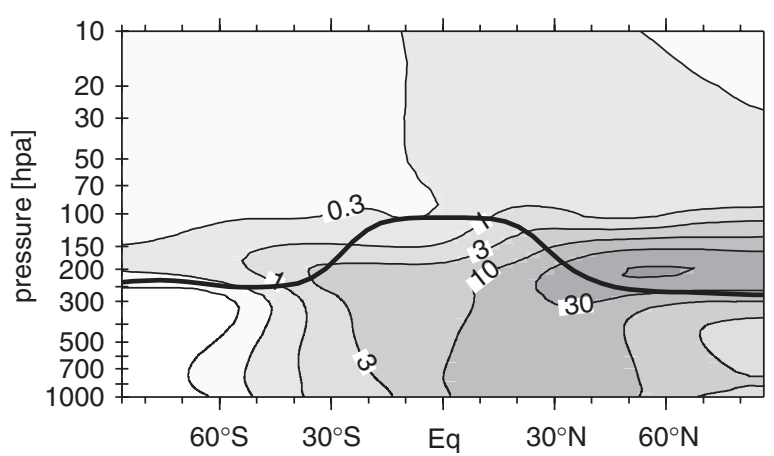

Fig. 3. Annual mean increase of water vapour mixing ratio (in nmol mol${ }^{-1}$ ) due to emissions of a purely $\mathrm{LH}_{2}$ fuelled air-fleet using the 2015 inventory, as simulated by the ECHAM4 global climate model. The thick contour indicates the tropopause of the model. 
Table 4

Input parameters for the linear response model: radiative forcing (in $\mathrm{mW} \mathrm{m}^{-2}$ ) of water vapour emitted by a pure cryoplane aviation in 2015

\begin{tabular}{lll}
\hline Scenario & RF $\left(\mathrm{mW} \mathrm{m}^{-2}\right)$ & Reference \\
\hline Min & 1.5 & Marquart et al. (2001) \\
Best & 2.8 & This study \\
Max & 6.5 & Gauss et al. (2003) \\
\hline
\end{tabular}

A best estimate, as well as minimum and maximum estimates are provided (see text for details).

We finally note that the climate sensitivity parameter for aircraft water vapour has been estimated from a simulation forced by the perturbation pattern shown in Fig. 3. In order to reach a sensible signal to noise ratio, however, this perturbation was artificially enhanced to a corresponding RF of $60 \mathrm{~mW} \mathrm{~m}^{-2}$ (instead of the original $2.8 \mathrm{~mW} \mathrm{~m}^{-2}$, Table 4). The resulting $\lambda$ value turned out to be similar to the $\mathrm{CO}_{2}$ reference value (Table 1).

\subsection{Greenhouse gas precursors: $\mathrm{NO}_{x}$}

The main greenhouse precursor to be considered here is $\mathrm{NO}_{x}$, which causes a climate impact by changing atmospheric ozone and, thereby, methane abundance. Numerous 3D model studies on aircraft induced ozone concentration change exist (see Penner et al., 1999; Sausen et al., 2005, and references therein), which produce a wide range of results as a consequence of model differences with respect to transport, chemistry, and radiation. Varying specification of external input like the aircraft $\mathrm{NO}_{x}$ EI or non-aviation $\mathrm{NO}_{x}$ sources add further uncertainties. Rescaling the uncertainty estimates of Penner et al. (1999, Table 6.1) to the emission inventories we adopt in the present study, the range of ozone RF is between $9.6 \mathrm{~mW} \mathrm{~m}^{-2}$ and $40 \mathrm{~mW} \mathrm{~m}^{-2}$ for the year 1992 (Table 5), and between 30 and $120 \mathrm{~mW} \mathrm{~m}^{-2}$ for the year 2050 . The more recent estimate of Sausen et al. (2005) is between 12 and $28 \mathrm{~mW} \mathrm{~m}^{-2}$ for the year 2000 , i.e. the spread slightly lowered but has remained considerable. We adopt the concept of Sausen and Schumann (2000) to calculate the RF from aviation ozone

$$
\begin{aligned}
\mathrm{RF}_{\mathrm{O}_{3}}(t)= & S_{\mathrm{O}_{3}} \cdot\left[(1-k) \cdot \frac{\mathrm{EI}\left(\mathrm{NO}_{x}\right)_{\mathrm{conv}}(t)}{\operatorname{EI}\left(\mathrm{NO}_{x}\right)_{\mathrm{conv}}(1992)}\right. \\
& \left.+k \cdot \frac{\mathrm{EI}\left(\mathrm{NO}_{x}\right)_{\mathrm{cryo}}(t)}{\operatorname{EI}\left(\mathrm{NO}_{x}\right)_{\mathrm{conv}}(1992)}\right] \cdot \frac{E_{a}(t)}{E_{a}(1992)},
\end{aligned}
$$

Table 5

Input parameters for the linear response model: radiative forcing (in $\mathrm{mW} \mathrm{m}^{-2}$ ) of ozone and methane caused by pure conventional aviation in 1992

\begin{tabular}{llcl}
\hline Gas & Scenario & RF $\left(\mathrm{mW} \mathrm{m}^{-2}\right)$ & Reference \\
\hline \multirow{3}{*}{$\mathrm{O}_{3}$} & Min & 9.6 & Penner et al. (1999) \\
& Best & 20.0 & Penner et al. (1999) \\
& Max & 40.0 & Penner et al. (1999) \\
& Min & -4.5 & \\
$\mathrm{CH}_{4}$ & Best & -9.4 & \\
& Max & -18.8 & \\
\hline
\end{tabular}

A best estimate, as well as minimum and maximum estimates are provided. The ozone RF values estimated by Penner et al. (1999) for 1992 had to be scaled to the DLR-1992 fuel inventory used in the present study. The methane RF values are derived through linear scaling by a factor of 0.47 (Sausen et al., 2005, see text).

where $S_{\mathrm{O}_{3}}$ represents the specific ozone forcing in 1992 (Table 5) and $\mathrm{EI}\left(\mathrm{NO}_{x}\right)$ indicates the $\mathrm{NO}_{x}$ EI. Extending over Eq. (12) of Sausen and Schumann (2000) the $k$-term describes the contribution of the cryoplane fleet to the aviation $\mathrm{NO}_{x}$ emission, which will of course depend on the time evolution of the EI values. Values for this evolution (Table 2) have been adopted from the CRYOPLANE project (Klug, 2001). For reasons mentioned in the introduction he has assumed a lower index for $\mathrm{LH}_{2}$ than for kerosene engines. However, gradual technological progress throughout the period after 2015 has been taken into account for both engine types, resulting in $\mathrm{EI}\left(\mathrm{NO}_{x}\right)$ values as low as $4.5 \mathrm{~g}\left(\mathrm{NO}_{2}\right) / \mathrm{kg}(\mathrm{ke})$ and $1.5 \mathrm{~g}\left(\mathrm{NO}_{2}\right) / \mathrm{kg}(\mathrm{ke})$ for conventional and cryoplane aircraft in 2050 , respectively.

It is further assumed implicitly by Eq. (5) that the $\mathrm{RF}$ of aircraft induced ozone increases linearly with aircraft $\mathrm{NO}_{x}$ emissions, an approximation derived by Grewe et al. (1999) from a large number of chemistry model results. The limits of this linearity assumption seem to introduce an uncertainty of about $20 \%$ for the calculated RF (Isaksen et al., 2001; Grewe et al., 2002a), which we deem smaller than other uncertainties discussed in this section (e.g., for the EI or the reference aircraft ozone forcing). The development of $\mathrm{NO}_{x}$ emission indices according to Table 2 and the RF of $20 \mathrm{~mW} \mathrm{~m}^{-2}$ (Penner et al., 1999, and Table 5) for 1992 conditions form the basis of our best estimate for the RF of aviation ozone. We also provide an alternative scenario ("EI high") where no technological progress for the conventional technology occurs. Furthermore, we form minimum 
and maximum estimates, scaling $S_{\mathrm{O}_{3}}$ either by a factor 0.5 in the main scenario or by a factor 2 in the EI high scenario, respectively (Table 5). The resulting wide range of uncertainty closely follows the IPCC considerations (Penner et al., 1999) reported above.

The total climate impact of aviation $\mathrm{NO}_{x}$ emissions must also include their direct and indirect effect on the atmospheric concentration of the hydroxyl radical and, thus, on the lifetime of methane (see Fuglestvedt et al., 1999, and references therein). The net $\mathrm{NO}_{x}$-methane radiative feedback is negative, i.e., it reduces part of the positive RF due to the aircraft induced ozone increase. Generally we adopt the simplified treatment introduced by Penner et al. (1999) to estimate the RF due to reduced methane lifetime by a constant factor:

$\mathrm{RF}_{\mathrm{CH}_{4}}(t)=-D \cdot \mathrm{RF}_{\mathrm{O}_{3}}(t)$.

From a review of ensemble chemistry simulations performed for the more recent TRADEOFF project, Sausen et al. (2005) have concluded that these results indicate a substantially smaller methane RF contribution. Therefore we do not use the factor of $D=0.67$ given by Penner et al. (1999) but rather the one derived from the TRADEOFF results, $D=0.47$. We emphasize that the uncertainty associated with the methane contribution must be regarded as even larger than for ozone, and that the competition between ozone and methane RF may be different for $\mathrm{NO}_{x}$ sources other than aviation. Hence, the linear treatment of methane RF adopted here is only acceptable on a global perspective and is applied in the absence of an established superior method.

In estimating the global temperature effect we account for the differences in the climate sensitivity of both methane changes and aircraft ozone changes in comparison to $\mathrm{CO}_{2}$ (Table 1). The $\lambda$ value for aviation ozone has been derived from a couple of simulations based on the perturbation patterns presented by Grewe et al. (2002a) and is by about $40 \%$ larger than the $\mathrm{CO}_{2}$ value. Aviation ozone increase is largest in northern polar and midlatitudes, a pattern that tends to enhance the forcing efficacy in comparison to horizontally homogeneous or low latitude perturbations (Berntsen et al., 2005). The efficacy of the methane forcing turned out to range between those of the $\mathrm{CO}_{2}$ and aviation ozone forcings. Hence, the net effect of aircraft $\mathrm{NO}_{x}$ emissions to global mean surface temperature will slightly exceed the relative contribution expected from the sum of ozone and methane RF.

\subsection{Contrails}

One of our main improvements over the pilot study of Marquart et al. (2001) is the inclusion of new results on the lower optical depth of cryoplane contrails in 3D simulations with ECHAM4. This information has been gained by deriving, by means of a microphysical model (Ström and Gierens, 2002), particle size distribution and effective ice crystal radius differences from contrail lifetime simulations for kerosene and $\mathrm{LH}_{2}$ aircraft. There are less but larger ice crystals in cryoplane contrails due to the absence of particles in the engine exhaust. ECHAM4 based RF calculations are available for the 1992, 2015, and 2050 inventories with pure kerosene fuel consumption from Marquart et al. (2003) and for the 2015 and 2050 inventories with pure $\mathrm{LH}_{2}$ consumption from Marquart et al. (2005). As an example, Fig. 4 shows the distribution of cryoplane induced contrails in 2015 with a corresponding global mean RF of $8.0 \mathrm{~mW} \mathrm{~m}^{-2}$, while the $\mathrm{RF}$ by conventional aviation from the same inventory would be $9.8 \mathrm{~mW} \mathrm{~m}^{-2}$ (Marquart et al., 2005). The best estimates of Marquart et al. (2005) indicate a moderate global RF reduction by about $20 \%$ in the cryoplane case for each time slice. For the present study a fictive cryoplane estimate has also been performed using the 1992 inventory. It yields a RF of $3.1 \mathrm{~mW} \mathrm{~m}^{-2}$ in contrast to the $3.5 \mathrm{~mW} \mathrm{~m}^{-2}$ estimated by Marquart et al. (2003) for kerosene supported 1992 aviation. The set of key numbers indicates some degree of nonlinearity in the time dependence of RF from fuel consumption and propulsion efficiency. However, as proposed by Schumann (2001) in extending the Sausen and Schumann (2000) model, the nonlinearity can be accounted for by a slight modification in the linear response function for $\operatorname{RF}_{\text {contrails }}(t)$, which we use here in the form:

$$
\begin{aligned}
\operatorname{RF}_{\text {contrails }}(t)= & {\left[S_{\text {contrails }}^{\text {conv }} \cdot(1-k) \cdot \frac{0.1+\eta_{\text {conv }}(t)}{0.1+\eta_{\text {conv }}(1992)}\right.} \\
& \left.+S_{\text {contrails }}^{\text {cryo }} \cdot k \cdot \frac{0.6+\eta_{\text {cryo }}(t)}{0.6+\eta_{\text {cryo }}(1992)}\right] \cdot \frac{E_{a}(t)}{E_{a}(1992)}
\end{aligned}
$$

Unlike Eqs. (4) and (5), the specific RF for contrails $\left(S_{\text {contrails }}\right)$ is provided separately for the conventional and the cryoplane case, using 1992 values as 

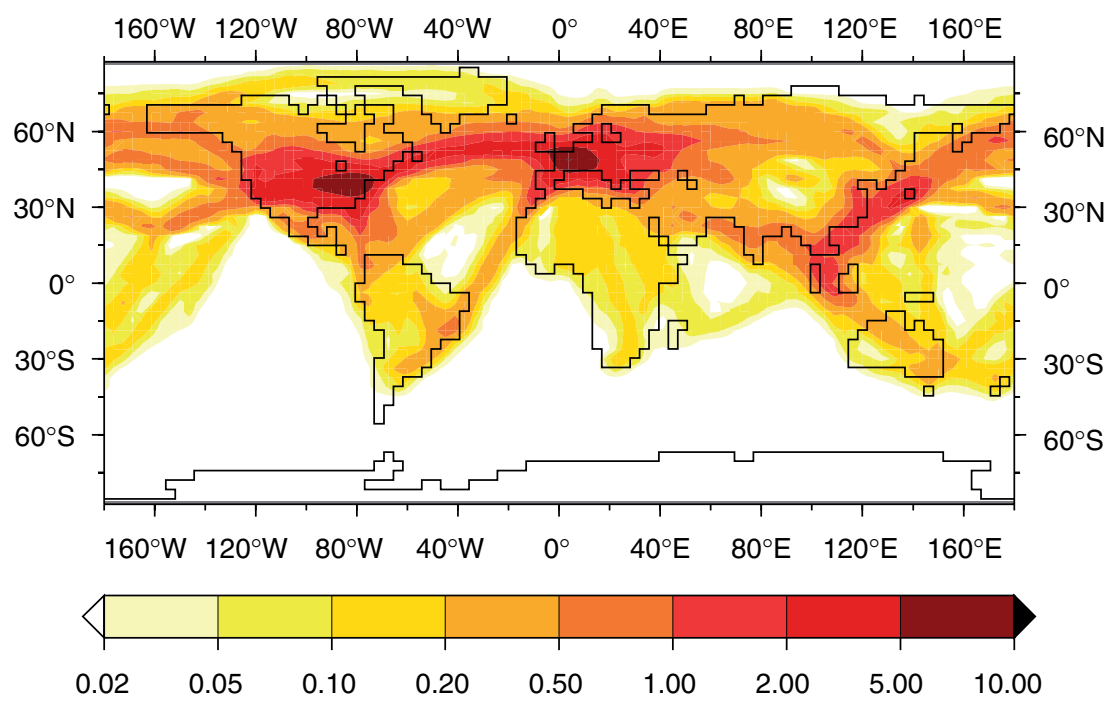

[\%]

Fig. 4. Annual mean contrail cover produced by a purely $\mathrm{LH}_{2}$ supported air-fleet for the 2015 aviation inventory, as simulated by the ECHAM4 global climate model.

Table 6

Input parameters for the linear response model: contrail $\mathrm{RF}\left(\mathrm{in} \mathrm{mW} \mathrm{m}^{-2}\right.$ ) for either pure conventional aviation or pure cryoplane aviation in 1992

\begin{tabular}{lccll}
\hline Scenario & Conv. & Cryopl. & Reference (Conv.) & Reference (Cryopl.) \\
\hline Min & 3.5 & 3.1 & Marquart et al. (2003) & This study \\
Best & 6.2 & 5.5 & Sausen et al. (2005) & Scaled, see text \\
Max & 17.0 & 15.0 & Minnis et al. (1999) & Scaled, see text \\
\hline
\end{tabular}

Best as well as minimum and maximum estimates are provided.

the basis (Table 6). Furthermore, the overall propulsion efficiencies $\eta$ (which are in fact expected to be the same for both technologies, see Table 2) are modified by an additive constant (Schumann, 2001). This means a tuning of the two terms of the right-hand side of Eq. (7) to fit the time development of the contrail RF calculated by the more comprehensive 3D model. We note that assuming equivalent overall propulsion efficiency for both technologies is consistent with results of the CRYOPLANE project (see Marquart et al., 2005, and references therein) with the possible $10 \%$ fuel use penalty mentioned in Section 2.3.

Marquart et al. (2005) have provided the most comprehensive approach to quantify contrail RF differences between kerosene and $\mathrm{LH}_{2}$ fuelled aircraft engines. However, the general magnitude of their contrail RF estimates is at the lower end in comparison to other calculations available for contrails from kerosene supported aviation (Minnis et al., 1999; Myhre and Stordal, 2001). The study of Minnis et al. (1999) formed the basis of the contrail best estimate in the IPCC report (Penner et al., 1999), indicating a $\mathrm{RF}$ of $17 \mathrm{~mW} \mathrm{~m}^{-2}$ for conventional air traffic in 1992 and, thus, being a factor five larger than the ECHAM4 based estimate for the same year (Marquart et al., 2003). However, Minnis et al. (1999) relied on regional observations (mainly over the United States) to derive contrail optical depth, which may not have given representative values for the globe. Based on more recent contrail studies Sausen et al. (2005) have replaced the IPCC best estimate by a new one $\left(10 \mathrm{~mW} \mathrm{~m}^{-2}\right.$ for 2000 conditions), still larger than the ECHAM4 values in Table 6. Hence, while we stay with Eq. (7) as derived from the ECHAM4 results, we use these key values $\left(S_{\text {contrails }}\right)$ only to define the minimum estimate. Our best estimate will follow the Sausen 
et al. (2005) assessment, whose values had to be scaled to a corresponding cryoplane estimate by the factor of 0.89 implied by the ECHAM4 results (Table 6). The same scaling procedure has been applied to form an upper estimate based on the Minnis et al. (1999) RF calculations.

Table 6 values only represent the RF of persistent line-shaped contrails. As discussed by Schumann (2005) total aviation induced cloudiness may exceed that impact considerably. The respective mechanisms are spreading of linear contrails by wind shear (contrail cirrus), and indirect effects due to particle accumulation in the UTLS. Currently, the amount of both impact components, as well as their sum, are highly uncertain: available estimates indicate a coverage larger by a factor between about 2 (Minnis et al., 2004) and about 10 (Mannstein and Schumann, 2005) in comparison to line-shaped contrails. Sausen et al. (2005) assess the current knowledge on total high cloud changes induced by conventional aviation as insufficient to define a RF best estimate. Sensible assumptions for characteristic optical properties for contrail cirrus from cryoplanes are even harder to make. As the simulations of Ström and Gierens (2002) indicate larger particle sizes in cryoplane contrails, further differences have to be expected for ice crystal sedimentation and lifetime between both contrail types. It is also not yet possible to decide which part of aircraft induced cirrus has to be attributed to either spreading contrails or indirect aerosol effects. Hence, total aircraft induced cirrus cannot reasonably be included in the linear response model calculations. We will return to this limitation of our assessment in the concluding discussion.

The efficacy $r$ for contrails (Table 1) has been provided and discussed by Ponater et al. (2005). It indicates the lowest value of all aviation contributions and, thus, reduces the importance of contrail $\mathrm{RF}$ for the surface temperature response.

\section{Climate impact change from technology transition}

We now present the differences of the global mean impact between the various transition scenarios. Fig. 5 shows the global RF development for all scenarios, separately for each component of the total effect. The figure also includes the maximum and minimum estimates. Note the individual scaling of the ordinate for various agents. Table 7 gives the $\mathrm{RF}$ values yielded for each component and for each scenario at the end of the transition period, i.e., in
2050. The best estimates are emphasized by bold numbers. Table 7, last column, also includes the percentage of the sum of RFs (relative to Ker) that remains in 2050 for the various estimates and transition scenarios.

As discussed in Section 3, the RF contributions of aviation $\mathrm{CO}_{2}$, ozone, and contrails are smaller in all transition scenarios than in the pure conventional scenario Ker. RF from $\mathrm{CO}_{2}$ basically follows the $\mathrm{CO}_{2}$ concentration (Fig. 2), again reflecting the large delay between changes in $\mathrm{CO}_{2}$ emissions and corresponding climate forcing. Even in the Cryo2 scenario, with its vanishing $\mathrm{CO}_{2}$ emissions at the end of the transition period, $\mathrm{CO}_{2} \mathrm{RF}$ will still be higher in 2050 than in 2015 due to atmospheric $\mathrm{CO}_{2}$ increase during most of the transition period. With respect to the $\mathrm{NO}_{x}$ effect, Fig. 5 displays only the evolution of ozone induced RF, which for the net impact will be damped by the methane contribution according to Eq. (6). The RF contribution of ozone drops rather rapidly after 2030 for all transition scenarios. By 2050 the RF reduction due to smaller ozone increase for cryoplanes is, for the best estimate, similar or even somewhat higher than the reduction effect contributed by $\mathrm{CO}_{2}$. For the cases assuming traditional combustion technology for conventional engines ("EI high", see $\mathrm{NO}_{x}$ emission indices in Table 2) the relative reduction of ozone $\mathrm{RF}$ would be quite substantial. Contrail RF is projected to be slightly smaller for the cryoplane scenarios compared to Ker, but still increases with time until 2050 for the Cryo1 and Cryo3 scenarios as the effect of increasing air traffic dominates over the reduction effect of the technology transition. As in Marquart et al. (2001) the water vapour RF increases in the cryoplane case, but by absolute magnitude this contribution remains the smallest. Only its maximum estimate is able to compete with the best estimate of contrail RF, which is the second smallest. The overall impression of the projected environmental gain is that all cryoplane scenarios give a smaller climate impact, in terms of RF in 2050 , indicating a RF reduction to between $54 \%$ and $85 \%$ relative to the reference scenario Ker. The early begin of the transition in Cryo 2 provides a definite advantage. This scenario clearly stands out as the most efficient one (even taking into account the considerable maximum to minimum range). Following the best estimates, the achievable reduction of the total aviation RF in 2050 would be $29 \%$, from about $128 \mathrm{~mW} \mathrm{~m}^{-2}$ in Ker to about $90 \mathrm{~mW} \mathrm{~m}^{-2}$ in Cryo2. 

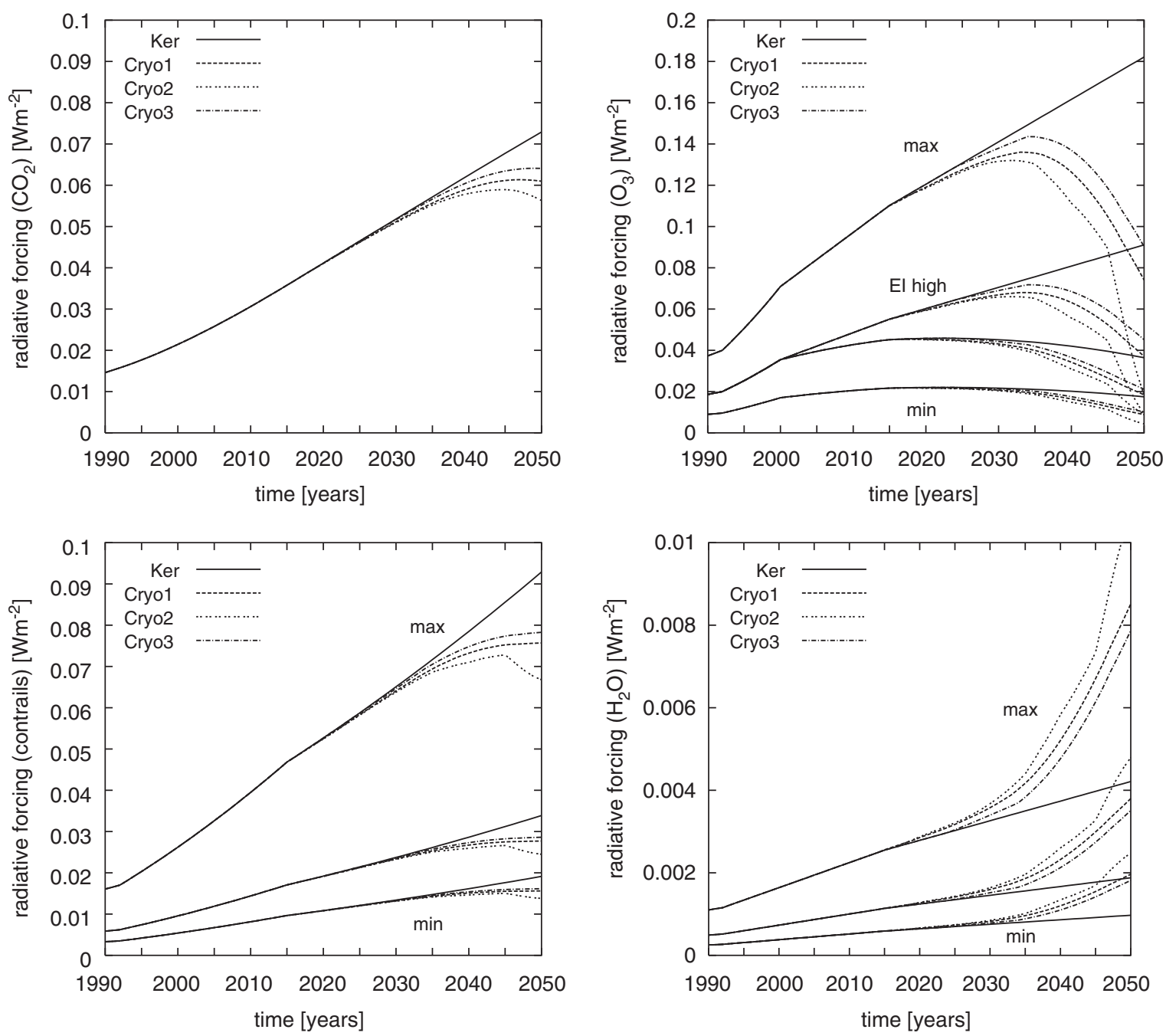

Fig. 5. Global mean radiative forcing (in $\mathrm{W} \mathrm{m}^{-2}$ ) due to conventional air traffic and cryoplane transition scenarios up to 2050 (separately for $\mathrm{CO}_{2}$, ozone, contrails, and water vapour).

Fig. 6 compares the best estimates for the time development of RF and for the surface temperature change, while Table 8 forms the counterpart to Table 7 in giving the climate impact change in terms of aviation induced surface temperature change for 2050 rather than in RF units. Evidently, the relative difference between the transition scenarios is much smaller if surface temperature changes are used as the metric of climate impact. The reason is the delay between forcing and response due to the thermal inertia of the climate system. The total aviation impact on surface temperature is smaller than in Ker for all transition scenarios. It is noteworthy that the reduction of temperature increase by cryoplane introduction receives the strongest contribution from $\mathrm{NO}_{x}$ emissions reduction (even including the methane effect), if the 2050 time horizon is considered. This is also a consequence of the high climate sensitivity of aviation ozone. If the same efficacy had been assumed for all forcings, $\mathrm{CO}_{2}$ would still contribute more than $\mathrm{NO}_{x}$ (via the sum of ozone and methane), as it does for the RF (Table 7). Likewise, due to the low efficacy of the contrail forcing the corresponding climate impact reduction almost cancels with the climate impact enhancement due to increasing water vapour accumulation, although these two effects barely influence the net effect of the technology switch 
Table 7

Results of linear response model: global radiative forcing (in $\mathrm{mW} \mathrm{m}^{-2}$ ) caused by conventional air traffic and cryoplane transition scenarios for 2050

\begin{tabular}{|c|c|c|c|c|c|c|c|c|}
\hline Scenario & & $\mathrm{CO}_{2}$ & $\mathrm{O}_{3}$ & $\mathrm{CH}_{4}$ & $\mathrm{H}_{2} \mathrm{O}$ & Contrails & Sum & Fraction \\
\hline \multirow[t]{4}{*}{ Ker } & Min & & 17.5 & -8.2 & 1.0 & 19.1 & 102.3 & \\
\hline & Best & 72.9 & 36.4 & -17.1 & 1.9 & 33.9 & 128.0 & \\
\hline & EIhigh & & 91.1 & -42.8 & & & 157.0 & \\
\hline & $\operatorname{Max}$ & & 182.1 & -85.6 & 4.2 & 92.9 & 266.5 & \\
\hline \multirow[t]{4}{*}{ Cryol } & Min & & 8.8 & -4.2 & 2.0 & 15.6 & 83.2 & $(81 \%)$ \\
\hline & Best & 61.0 & 18.4 & -8.7 & 3.8 & 27.7 & 102.2 & $(80 \%)$ \\
\hline & EIhigh & & 37.1 & -17.4 & & & 112.2 & $(71 \%)$ \\
\hline & $\operatorname{Max}$ & & 74.1 & -34.8 & 8.5 & 75.7 & 184.5 & $(69 \%)$ \\
\hline \multirow[t]{4}{*}{ Cryo2 } & Min & & 4.4 & -2.1 & 2.5 & 13.8 & 74.9 & $(73 \%)$ \\
\hline & Best & 56.3 & 9.1 & -4.3 & 4.8 & 24.5 & 90.4 & $(71 \%)$ \\
\hline & EIhigh & & 9.1 & -4.3 & & & 90.4 & $(58 \%)$ \\
\hline & $\operatorname{Max}$ & & 18.2 & -8.6 & 10.7 & 66.8 & 143.4 & $(54 \%)$ \\
\hline \multirow[t]{4}{*}{ Cryo3 } & Min & & 10.1 & -4.8 & 1.8 & 16.1 & 87.3 & $(85 \%)$ \\
\hline & Best & 64.1 & 21.1 & -9.9 & 3.5 & 28.6 & 107.4 & $(84 \%)$ \\
\hline & EIhigh & & 45.2 & -21.2 & & & 120.2 & $(77 \%)$ \\
\hline & $\operatorname{Max}$ & & 90.3 & -42.2 & 7.8 & 78.3 & 198.3 & $(74 \%)$ \\
\hline
\end{tabular}

Values in brackets gives the total radiative forcing in the "Cryo" scenarios relative to the respective estimate of the "Ker" scenario (in \%).
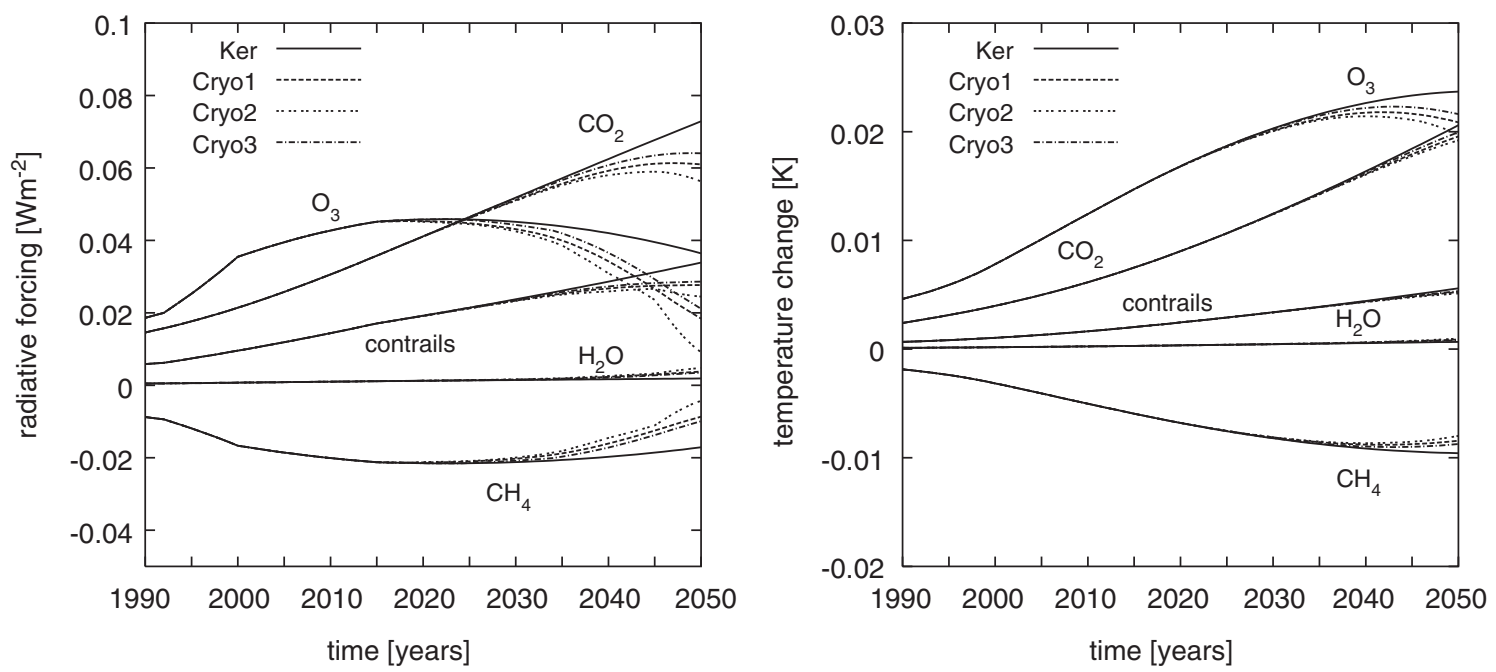

Fig. 6. Global mean radiative forcing (in $\mathrm{W} \mathrm{m}^{-2}$ ) and temperature change (in $\mathrm{K}$ ) due to conventional air traffic and cryoplane transition scenarios up to 2050 (all components).

(Fig. 6, right). The best estimates for climate impact reduction due to cryoplane transition in terms of surface temperature indicate a potential reduction to between $90 \%$ and $95 \%$ of the impact expected for Ker in 2050. If all minimum and maximum estimates are considered too, the range widens to between $83 \%$ and $96 \%$ (Table 8 ). Longer time horizons will be discussed in the concluding section.

\section{Discussion and conclusions}

In this study we have used state-of-the-art knowledge about the environmental effects of 
Table 8

Results of linear response model: global temperature change (in $\mathrm{mK}$ ) caused by conventional air traffic and cryoplane transition scenarios for 2050

\begin{tabular}{|c|c|c|c|c|c|c|c|c|}
\hline Scenario & & $\mathrm{CO}_{2}$ & $\mathrm{O}_{3}$ & $\mathrm{CH}_{4}$ & $\mathrm{H}_{2} \mathrm{O}$ & Contrails & Sum & Fraction \\
\hline \multirow[t]{4}{*}{ Ker } & Min & & 11.4 & -4.6 & 0.3 & 3.2 & 30.9 & \\
\hline & Best & 20.6 & 23.7 & -9.6 & 0.7 & 5.6 & 41.0 & \\
\hline & EIhigh & & 38.2 & -15.4 & & & 49.7 & \\
\hline & Max & & 76.4 & -30.9 & 1.5 & 15.3 & 82.9 & \\
\hline \multirow[t]{4}{*}{ Cryol } & Min & & 10.0 & -4.0 & 0.4 & 3.0 & 29.0 & $(94 \%)$ \\
\hline & Best & 19.6 & 20.9 & -8.4 & 0.9 & 5.3 & 38.3 & $(93 \%)$ \\
\hline & EIhigh & & 31.1 & -12.6 & & & 44.3 & $(89 \%)$ \\
\hline & Max & & 62.2 & -25.1 & 2.0 & 14.4 & 73.1 & $(88 \%)$ \\
\hline \multirow[t]{4}{*}{ Cryo2 } & Min & & 9.5 & -3.8 & 0.5 & 2.9 & 28.3 & $(92 \%)$ \\
\hline & Best & 19.2 & 19.8 & -8.0 & 1.0 & 5.1 & 37.1 & $(90 \%)$ \\
\hline & EIhigh & & 28.3 & -11.4 & & & 42.2 & $(85 \%)$ \\
\hline & $\operatorname{Max}$ & & 56.6 & -22.9 & 2.2 & 14.0 & 69.1 & $(83 \%)$ \\
\hline \multirow[t]{4}{*}{ Cryo3 } & Min & & 10.4 & -4.2 & 0.4 & 3.0 & 29.6 & $(96 \%)$ \\
\hline & Best & 20.0 & 21.6 & -8.7 & 0.8 & 5.3 & 39.0 & $(95 \%)$ \\
\hline & EIhigh & & 32.8 & -13.3 & & & 45.6 & $(92 \%)$ \\
\hline & $\operatorname{Max}$ & & 65.7 & -26.6 & 1.8 & 14.6 & 75.5 & $(91 \%)$ \\
\hline
\end{tabular}

Values in brackets gives the total temperature change due to the "Cryo" scenarios relative to the respective estimate of the "Ker" scenario (in \%).
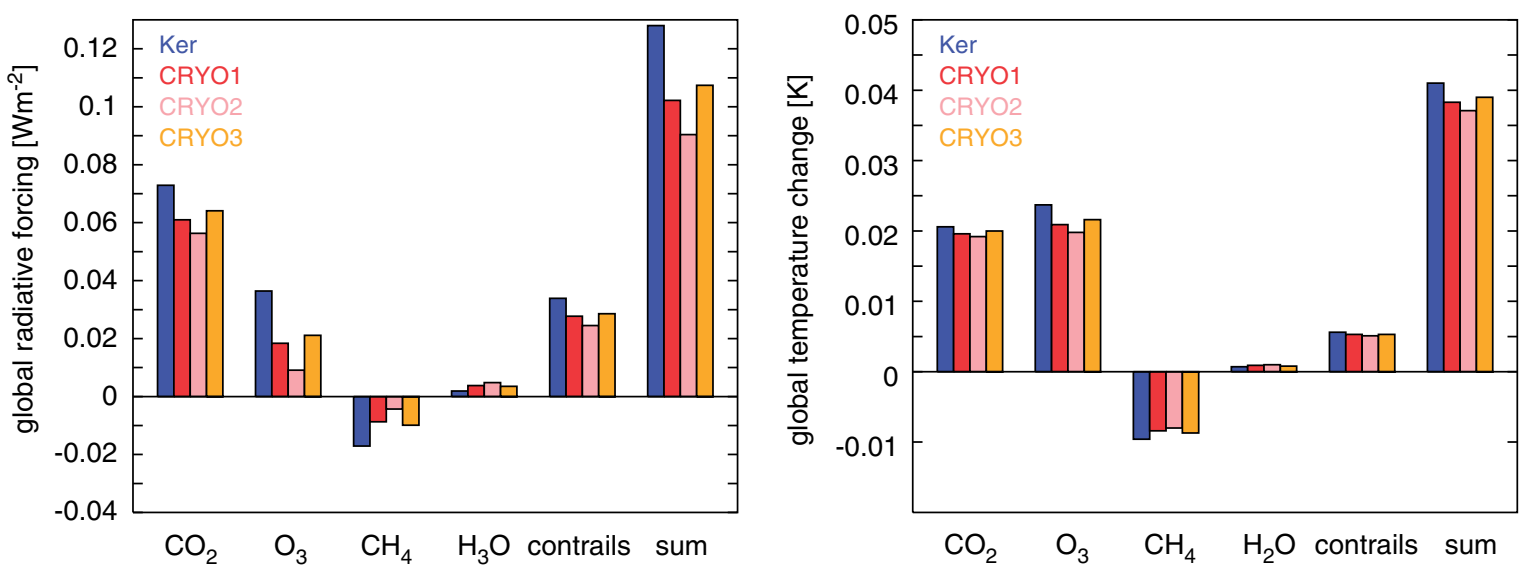

Fig. 7. Total global radiative forcing (in $\mathrm{W} \mathrm{m}^{-2}$ ) and temperature change (in $\mathrm{K}$ ) at the 2050 time horizon, as caused by a conventional air traffic scenario and several cryoplane transition scenarios according to the best estimates listed in Tables 7 and 8 .

kerosene and liquid hydrogen $\left(\mathrm{LH}_{2}\right)$ fuelled aircraft to assess the potential of a gradual switch to the cryoplane technology for reducing the aviation induced global climate impact. As summarized in Fig. 7, the cryoplane transition scenarios indicate a reduction of radiative forcing (RF) by up to $30 \%$ (about $40 \mathrm{~mW} \mathrm{~m}^{-2}$ ) and of global mean surface temperature increase by up to $10 \%$ (about $4 \mathrm{mK}$ ) at the 2050 time slice. These numbers depend on a delicate balance between various contributing effects, which in some cases contain a considerable quantitative uncertainty. Nevertheless we can conclude that the possibility of an even enhanced climate impact due to cryoplane introduction (Marquart et al., 2001) can now be excluded.

Fig. 7 also illustrates the relative importance of individual effects according to our best estimate: the largest beneficial contribution arises from the avoidance of $\mathrm{CO}_{2}$ emissions and the higher potential of reducing $\mathrm{NO}_{x}$ emissions in case of $\mathrm{LH}_{2}$ 
supported aircraft engines. The climate impact of aircraft emitted water vapour accumulating at cruising altitudes remains weak (as long as current flight levels are retained). The net effect of cryoplane contrails is likely to be less positive than for contrails from conventional aircraft, because smaller optical depth dominates over higher occurrence frequency on the global scale. However, the contrail contribution to the environmental gain is less important than the contribution arising from $\mathrm{CO}_{2}$ and $\mathrm{NO}_{x}$ emissions decrease in the cryoplane case. We have not included the direct radiative effect of particle emissions in the bar charts of Fig. 7, because it has not been re-evaluated in this study. However, it does not seem to be of relevance that this effect will vanish for cryoplane aviation, because it is already quite small in case of conventional aviation (Penner et al., 1999).

Indirect particle emission effects through aircraft induced cirrus may be more crucial. With current knowledge in mind, the absence of aviation induced cirrus in the "sum of effects" displayed in Fig. 7 forms an important limit to our assessment. However, we deem the scientific basis to draw quantitative conclusions to be insufficient for assessment purposes. Concerning the cryoplane aspect, any progress to achieve a best estimate for aviation induced cirrus requires that the relative importance of spreading contrails and microphysical effects arising from aerosol accumulation in the UTLS can be quantified by advanced model frameworks. Respective concepts have recently been developed (Kärcher et al., 2006), but aircraft related results so far have remained preliminary (Hendricks et al., 2005). We expect that measurements in contrails forming behind a cryoplane prototype will be necessary, in order to evaluate respective future model calculations. Anyway, if the cirrus increase $\mathrm{RF}$ induced by conventional aviation were as large as the maximum estimate of Sausen et al. (2005), this would suggest an even enhanced environmental benefit of cryoplanes: These do not emit particles (meaning no indirect effect due to background aerosol accumulation) and cause contrails with smaller optical depth and, potentially, a shorter lifetime (see Section 3.3). Working in the other direction there will be more line-shaped contrails to spread, but there is no reason why this could lead to a stronger counter effect than in case of the lineshaped contrails (Marquart et al., 2005).

Other assumptions entering our assessment have already been mentioned: we presume a linear dependency between emissions and radiative impact for spatially inhomogeneous climate forcings as contrails or aircraft induced ozone. This may be justified only as long as the air traffic density pattern with respect to latitude and altitude does not substantially change with time. The way in which methane lifetime changes are considered is certainly a crude one. Feedbacks of background climate change to the aircraft perturbations have not been included here. All these shortcomings, however, seem to be acceptable, because they imply uncertainties within the range given in the IPCC special report (Penner et al., 1999). The general uncertainty considerations expressed by Penner et al. (1999) continue to be valid anyway. At least, our main goal to quantify relative differences between the technology option should not be significantly affected.

There are two further caveats that need to be addressed here: running an infrastructure for cryoplane operation may include the release of more hydrogen to the environment, with possible consequences for tropospheric and stratospheric chemistry (Tromp et al., 2003; Schultz et al., 2003; Warwick et al., 2004). Current estimates, however, are not reliable enough to enter this assessment. Our assumption of zero $\mathrm{CO}_{2}$ emissions for $\mathrm{LH}_{2}$ engines (Table 3) is only justified if all $\mathrm{LH}_{2}$ needed to supply a world-wide air-fleet can be provided by renewable energy sources. As soon as any $\mathrm{CO}_{2}$ is emitted during the $\mathrm{LH}_{2}$ production process (or, precisely, if $\mathrm{LH}_{2}$ production requires more fossil fuel burning than kerosene production), the gain suggested by Figs. 1 and 2 will decrease accordingly. There are no reliable data about the future development of renewable energy sources available to include this aspect in the assessment, but the presumption has to be emphasized as part of our quantitative conclusions.

Finally, it is important to note that the advantage of the $\mathrm{CO}_{2}$ avoidance would become more obvious for longer time horizons. There are no credible aircraft inventories for the time after 2050. However, if we assume constant aircraft fuel consumption and emissions on the 2050 level for the subsequent 50 years, the $\mathrm{CO}_{2}$ related RF in the kerosene scenario (Ker) will continue to increase, while it will not for the cryoplane scenarios where zero $\mathrm{CO}_{2}$ emissions occur shortly after 2050, as soon as the transition will be completed. Fig. 8 illustrates what this would mean for the aviation induced surface temperature change: the potential of cryoplane related temperature impact reduction would 

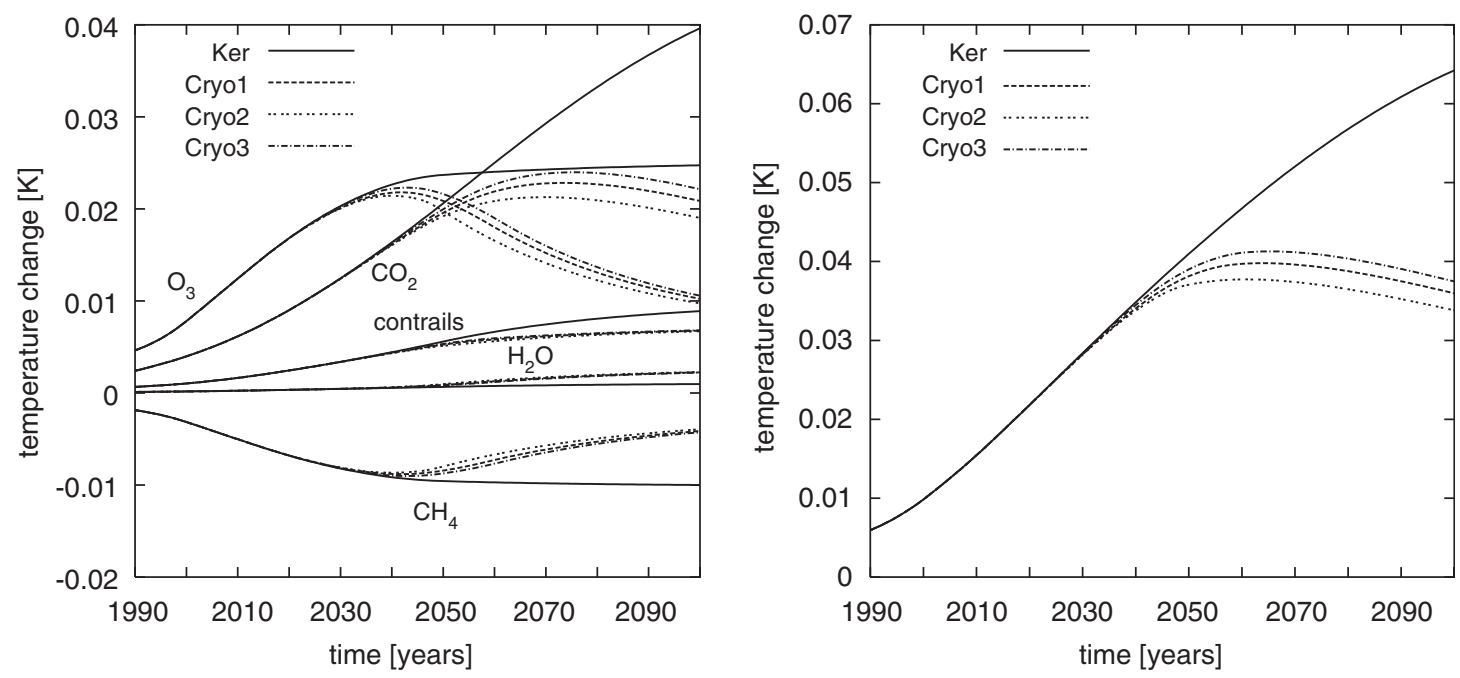

Fig. 8. Simulation of global mean surface temperature change (in K) due to conventional air traffic and for cryoplane transition scenarios for a period up to 2100. Left panel displays the individual components that sum up to give the total effect shown in the right panel. The fuel consumption for years between 2050 and 2100 is fixed to 2050 conditions.

increase from the above mentioned $10 \%$ range in 2050 to about $45 \%$ in 2100 . Total RF at 2100 (not shown) would be reduced by between $50 \%$ to $60 \%$, depending on the specific transition scenario. (These values imply again zero $\mathrm{CO}_{2}$ emissions in the cryoplane scenario.) It is apparent that, with transition scenarios as employed in this study, the environmental benefits of the cryoplane technology would evolve mainly on timescales of 50 years and longer.

\section{Acknowledgements}

Substantial parts of this study were funded by the EU projects CRYOPLANE and TRADEOFF under Grants G4RD-CT-2000-00192 and EVK2CT-1999-00030, respectively. We gratefully acknowledge the helpful discussions with HeinzGünter Klug, Michael Gauss, Volker Grewe, and Christine Fichter. The Ph.D. thesis of the second author (under her birthname Susanne Marquart) contributed significantly to this study and was supported by the Studienstiftung des deutschen Volkes. Funding from the EU network ECATS helped to complete this assessment.

\section{References}

Berntsen, T.K., Fuglestvedt, J.S., Joshi, M.M., Shine, K.P., Stuber, N., Ponater, M., Sausen, R., Hauglustaine, D.A., Li, L., 2005. Response of climate to regional emissions of ozone precursors: sensitivities and warming potentials. Tellus 57B, 283-304.

Brasseur, G., Cox, R., Hauglustaine, D., Isaksen, I., Lelieveld, J., Lister, D., Sausen, R., Schumann, U., Wahner, A., Wiesen, P., 1998. European scientific assessment of the atmospheric effect of aircraft emissions. Atmospheric Environment 32, 2329-2418.

Dahl, G., Suttrop, F., 1998. Engine control and low-NO combustion for hydrogen fuelled aircraft gas turbines. International Journal of Hydrogen Energy 23, 695-704.

Fichter, C., Marquart, S., Sausen, R., Lee, D.S., 2005. The impact of cruise altitude on contrails and related radiative forcing. Meteorologische Zeitschrift 14, 563-572.

Forster, P.M.F., Shine, K.P., Stuber, N., 2006. It is premature to include non $\mathrm{CO}_{2}$ effects of aviation in emission trading schemes. Atmospheric Environment 40, 1117-1121.

Fuglestvedt, J.S., Berntsen, T.K., Isaksen, I.S.A., Mao, H., Liang, X.-Z., Wang, W.-C., 1999. Climatic forcing of nitrogen oxides through changes in tropospheric ozone and methane; global 3D model studies. Atmospheric Environment 33, 961-977.

Fuglestvedt, J.S., Berntsen, T.K., Godal, O., Sausen, R., Shine, K.P., Skodvin, T., 2003. Metrics of the climate change: assessing radiative forcing and emission indices. Climatic Change 58, 267-331.

Gauss, M., Isaksen, I.S.A., Wong, S., Wang, W.-C., 2003. The impact of $\mathrm{H}_{2} \mathrm{O}$ emissions from cryoplanes and kerosene aircraft on the atmosphere. Journal of Geophysical Research $108,4304$.

Gauss, M., Isaksen, I.S.A., Lee, D.S., Søvde, O.A., 2006. Impact of aircraft $\mathrm{NO}_{x}$ emissions on the atmosphere-tradeoffs to reduce the impact. Atmospheric Chemistry and Physics 6, 1529-1548.

Grewe, V., Dameris, M., Hein, R., Köhler, I., Sausen, R., 1999. Impact of future subsonic aircraft $\mathrm{NO}_{x}$ emissions on the atmospheric composition. Geophysical Research Letters 26, 47-50. 
Grewe, V., Brunner, D., Dameris, M., Grenfell, J.L., Hein, R., Shindell, D., Staehelin, J., 2001. Origin and variability of upper tropospheric nitrogen oxides and ozone at northern mid-latitudes. Atmospheric Environment 35, 3421-3433.

Grewe, V., Dameris, M., Fichter, C., Sausen, R., 2002a. Impact of aircraft $\mathrm{NO}_{x}$ emissions. Part 1: interactively coupled climate chemistry simulations and sensitivities to climatechemistry feedback, lighting and resolution. Meteorologische Zeitschrift 11, 177-186.

Grewe, V., Dameris, M., Fichter, C., Lee, D.S., 2002b. Impact of aircraft $\mathrm{NO}_{x}$ emissions. Part 2: effects of lowering the flight altitude. Meteorologische Zeitschrift 11, 197-205.

Hansen, J., Sato, M., Ruedy, R., Nazarenko, L., Lacis, A., Schmidt, G.A., Russell, G., et al., 2005. Efficacy of climate forcings. Journal of Geophysical Research 110, D18104.

Hein, R., Dameris, M., Schnadt, C., Land, C., Grewe, V., Köhler, I., Ponater, M., Sausen, R., Steil, B., Landgraf, J., Brühl, C., 2001. Results of an interactively coupled atmospheric chemistry-general circulation model: comparison with observations. Annales Geophysicae 19, 435-457.

Hendricks, J., Kärcher, B., Lohmann, U., Ponater, M., 2005. Do aircraft black carbon emissions affect cirrus clouds on the global scale? Geophysical Research Letters 32, L12814.

Hüttig, G., Kappers, A., Essers, I., 2001. Global transition scenarios. Task final report 8.5-1 within EU project CRYOPLANE, Fifth Framework Programme of the European Communities, 35pp.

Isaksen, I.S.A., Berntsen, T.K., Wang, W.-C., 2001. $\mathrm{NO}_{x}$ emissions from aircraft: its impact on the global distribution of $\mathrm{CH}_{4}$ and $\mathrm{O}_{3}$ and on radiative forcing. Terrestrial Atmospheric and Oceanic Sciences 12, 63-78.

Kärcher, B., Hendricks, J., Lohmann, U., 2006. Physically based parameterization of cirrus cloud formation for use in atmospheric models. Journal of Geophysical Research 111, D01205.

Kinnison, D.E., Connell, P.S., Rodriguez, J.M., Rotman, D.A., Considine, D.B., Tannahill, J., Ramaroson, R., Rasch, P.J., Douglass, A.R., Baughcum, S.L., Coy, L., Waugh, D.W., Kawa, S.R., Prather, M.J., 2001. The global modeling initiative assessment model: application to high-speed civil transport perturbation. Journal of Geophysical Research 106, 1693-1711.

Klug, H.G., 2001. Preliminary data for $\mathrm{NO}_{x}$-emissions of kerosene and hydrogen engines. Task Technical Report 1.16 within EU project CRYOPLANE, Fifth Framework Programme of the European Communities, 7pp.

Land, C., Ponater, M., Sausen, R., Roeckner, E., 1999. The ECHAM4.L39(DLR) atmosphere GCM: Technical description and model climatology. DLR-Forschungsbericht No. 1991-31, Deutsche Zentrum für Luft-und Raumfahrt, Oberpfaffenhofen, Germany, 45pp.

Mannstein, H., Schumann, U., 2005. Aircraft induced contrail cirrus over Europe. Meteorologische Zeitschrift 14, 549-554.

Mannstein, H., Spichtinger, P., Gierens, K., 2005. A note on how to avoid contrail cirrus. Transportation Research D 7, 421-426.

Marquart, S., Sausen, R., Ponater, M., Grewe, V., 2001. Estimate of the climate impact of cryoplanes. Aerospace Science and Technology 5, 73-84.

Marquart, S., Ponater, M., Mager, F., Sausen, R., 2003. Future development of contrail cover, optical depth, and radiative forcing: impacts of increasing air traffic and climate change. Journal of Climate 16, 2890-2904.

Marquart, S., Ponater, M., Ström, L., Gierens, K., 2005. An upgraded estimate of the radiative forcing of cryoplane contrails. Meteorologische Zeitschrift 14, 573-582.

Meyer, R., Büll, R., Leiter, C., Mannstein, H., Pechtl, S., Oki, T., Wendling, P., 2006. Contrail observations over southern and eastern Asia in NOAA/AVHRR data and intercomparison to contrail simulation in a GCM. International Journal of Remote Sensing, 27, in press.

Minnis, P., Schumann, U., Doelling, D.R., Gierens, K., Fahey, D.W., 1999. Global distribution of contrails radiative forcing. Geophysical Research Letters 26, 1853-1856.

Minnis, P., Ayers, K., Palikonda, R., Phan, D., 2004. Contrails, cirrus trends, and climate. Journal of Climate 17, 1671-1685.

Morris, G.A., Rosenfield, J.E., Schoeberl, M.R., Jackman, C.H., 2003. Potential impact of subsonic and supersonic aircraft exhaust on water vapour in the lower stratosphere assessed via a trajectory model. Journal of Geophysical Research 108, 4103.

Myhre, G., Stordal, F., 2001. On the tradeoff of the solar and the thermal infrared radiative impact of contrails. Geophysical Research Letters 28, 3119-3122.

Penner, J.E., Lister, D.H., Griggs, D.J., Dokken, D.J., McFarland, M., 1999. Intergovernmental Panel on Climate Change (IPCC) Aviation and the Global Atmosphere. Cambridge University Press, New York, 365pp (special report).

Ponater, M., Marquart, S., Sausen, R., Schumann, U., 2005. On contrail climate sensitivity. Geophysical Research Letters 32, L10706.

Ponater, M., Stenke, A., Grooß, J.-U., Brühl, C., 2006. Lower stratospheric moist bias and cold bias in GCMs. In preparation.

Ramaswamy, V., Boucher, O., Haigh, J., Hauglustaine, D.A., Haywood, J., Myhre, G., Nakajima, T., Shi, G.Y., Solomon, S., et al., 2001. Radiative forcing of climate change. In: Houghton, J.T., et al. (Eds.), Climate Change 2001: The Scientific Basis Intergovernmental Panel on Climate Change. Cambridge University Press, Cambridge, New York, pp. 349-416.

Roeckner, E., Arpe, K., Bengtsson, L., Christoph, M., Claussen, M., Dümenil, L., Esch, M., Giorgetta, M., Schlese, U., Schulzweida, U., 1996. The atmospheric general circulation model ECHAM-4: Model description and simulation of present-day climate. Report No. 218, Max-Planck-Institut für Meteorologie, Hamburg, Germany, 90pp.

Sausen, R., Schumann, U., 2000. Estimates of the climate response to aircraft $\mathrm{CO}_{2}$ and $\mathrm{NO}_{x}$ emissions scenarios. Climatic Change 44, 27-58.

Sausen, R., Isaksen, I., Grewe, V., Hauglustaine, D., Lee, D.S., Myhre, G., Köhler, M.O., Pitari, G., Schumann, U., Stordal, F., Zerefos, C., 2005. Aviation radiative forcing in 2000. An update on IPCC (1999). Meteorologische Zeitschrift 14, 555-561.

Schultz, M., Diehl, T., Brasseur, G.P., Zittel, W., 2003. Air pollution and climate forcing impacts of a global hydrogen economy. Science 302, 624-627.

Schumann, U., 1996. On conditions for contrail formation from aircraft exhausts. Meteorologische Zeitschrift 5, 4-23.

Schumann, U., 2000. Influence of propulsion efficiency on contrail formation. Aerospace Science and Technology 4, 391-401. 
Schumann, U., 2001. Climate sensitivity to contrails for increasing propulsion efficiency. In: Schumann, U., Amanatidis, G.T. (Eds.), Aviation, Aerosols, Contrails and Cirrus Clouds $\left(\mathrm{A}^{2} \mathrm{C}^{3}\right)$. European Commission, Brussels, pp. 271-274.

Schumann, U., 2005. Formation, properties and climate effects of contrails. Comptes Rendus Physique 6, 549-565.

Schumann, U., Ström, J., Arnold, F., Berntsen, T.K., Forster, P.M.de F., Gayet, J.-F., Hauglustaine, D., 2001. Aviation impact on atmospheric composition and climate. In: European Research in the Stratosphere 1996-2000. European Commission, Brussels, pp. 257-307.

Shine, K.P., Derwent, R.G., Wuebbles, D.J., Morcrette, J.-J., 1990. Radiative forcing of climate. In: Houghton, J.T., et al. (Eds.), Climate change: The IPCC Scientific Assessment. Cambridge University Press, Cambridge, New York, pp. 41-68.

Shine, K.P., Berntsen, T.K., Fuglestvedt, J.S., Sausen, R., 2005a. Scientific issues in the design of metrics for the inclusion of oxides of nitrogen in global climate agreements. Proceedings of the National Academy of Sciences of the United States of America 102, 15768-15773.

Shine, K.P., Fuglestvedt, J.S., Hailemariam, K., Stuber, N., 2005b. Alternatives to the global warming potential for comparing climate impacts of emissions of greenhouse gases. Climatic Change 68, 281-302.

Slingerland, R., 2005. Aircraft with $\mathrm{LH}_{2}$ propulsion. In: VKI Lecture Series Monographs on Innovative Configurations and Advanced Concepts for Future Civil Aircraft, Von Karman Institute Report LS 2005-06, Brussels, 47pp.

Stevenson, D.S., Johnson, C.E., Collins, W.J., Derwent, R.G., Edwards, J.M., 2000. Future estimates of tropospheric ozone radiative forcing and methane turnover - the impact of climate change. Geophysical Research Letters 27, 2073-2076.

Ström, L., Gierens, K., 2002. First simulations of cryoplane contrails. Journal of Geophysical Research 107, 4346.

Stuber, N., Sausen, R., Ponater, M., 2001. Stratosphere adjusted radiative forcing calculations in a comprehensive climate model. Theoretical and Applied Climatology 68, 125-135.

Svensson, F., Hasselrot, A., Moldanova, J., 2004. Reduced environmental impact by lowered cruise altitude for liquid hydrogen-fuelled aircraft. Aerospace Science and Technology $8,307-320$.

Tromp, T.K., Shia, R.-L., Allen, M., Eiler, J.M., Yung, Y.L., 2003. Potential environmental impact of a hydrogen economy on the stratosphere. Science 300, 1740-1742.

Warwick, N.J., Bekki, S., Nisbet, E.G., Pyle, J.S., 2004. Impact of a hydrogen economy on the stratosphere and troposphere studied in a 2-D model. Geophysical Research Letters 31, L05107.

Williams, V., Noland, R.B., Toumi, R., 2003. Air transport cruise altitude restrictions to minimize contrail formation. Climate Policy 3, 207-219. 